\title{
COMPATIBILITY OF TEACHING STYLES WITH LEARNING STYLES: A CASE STUDY
}

\author{
Saud Aldajah,PhD \\ Yousef Haik, PhD \\ Kamal Moustafa, PhD
}

Department of Mechanical Engineering, United Arab Emirates University, Al Ain - P.O. Box 15551, United Arab Emirates

\begin{abstract}
In order to enhance teaching quality and improve its effectiveness, attention must be paid to the compatibility of the instructors' teaching styles versus the students' learning styles, which play a vital role in how much knowledge the students can gain from the material presented in class. This paper presents the results of a study carried out on the mechanical engineering students and their instructors at the United Arab Emirates University. Results showed that the students learning styles are balanced: active-reflective, intuitive-sensor, visual-verbal and they prefer global over the sequential learning style. Moreover, the instructor's teaching styles were a mix of expert, formal-authority, personal-model and delegator. This spectrum of teaching addresses most of the students learning methods, which reflects positively on the learning process. This paper provides recommendations that instructors can implement in order to furthermore enhance the teaching process.
\end{abstract}

Keywords: Teaching styles, Learning styles, Compatibility

\section{Introduction}

Students vary in the way they receive and process information; this is due to the fact that they have different learning styles. Knowledge of students' learning styles can assist educators in planning their classes to ensure reaching each major style with planned activities. “...like all other teaching tools, knowledge of learning styles can work only if other qualities of good teaching are also prevalent” Mamchur, 1996.

Learning styles are defined as "a certain specified pattern of behavior and/or performance, according to which the individual takes in new information and develops new skills, and the process by which the individual retains new information or new skills" Sarasin,1999. Learning styles are 
characterized as how people acquire and understand new knowledge and skills. Thus a student's learning style is closely related to the way in which he actually processes and retains the information about that new skill or knowledge he is given. Students will generally have trouble processing information in one way and trying to learn or be assessed on that information in a method that is unsuitable for them. "When a teaching style doesn't meet the needs of a particular learning style, not much learning takes place" Gregorc, 1984.

Instructors develop a teaching style based on their beliefs about what constitutes good teaching, personal preferences, their abilities, and the norms of their particular discipline. Some believe classes should be teachercentered, where the teacher is the expert and authority in presenting information, Anthony, 1996. Others take a learner-centered approach, viewing their role as more of a facilitator of student learning. Although individuals have a dominant, preferred teaching style, they will often mix in some elements of other styles.

There are extreme differences in how people process information and learn. Constructivist, student-centered teaching focuses on teaching for understanding rather than covering the curriculum. Student-centered teachers create learning environments (in the classroom or online) which encourage learners to examine their current beliefs, enable them to explore and be exposed to new ways of thinking, and include experiences which require them to re-formulate their understanding. Instructors and designers of learning experiences should have an awareness of the diversity of learning styles which allows them to include features that appeal to different kinds of learners and helps students get the most out of their learning experience. This approach needs not to be taken to the extreme, but often small modifications to a basic design can dramatically expand its utility for different learning styles. Instruction which focuses on development of the "whole brain", including intuition, sensing, imagination as well as analysis, reason and sequential problem solving will reach a greater portion of students with various learning styles.

Carolyn Mamchur, 1996 says, "Understanding individual learning preferences and differences is an increasingly popular and useful tool, serving teachers in four ways. First, teachers have a method to teach that is diverse and adaptive enough to meet the various learning style needs of students who are not necessarily oriented toward schooling. Second, teachers can indicate to students that they care about the individuality and integrity of each learner. Third, because learning style is related to teaching style, teachers can better understand their own teaching styles strengths and weaknesses. And fourth, teachers can gain insight into how they work together in this particular world we call school.” 
Students will gain more knowledge, retain more information, and perform far better when teaching styles match learning styles, Lage, 2000. However, it is recognized that it is difficult to match with every learning style and therefore, a portfolio of teaching styles is recommended, Moallem, 2001.

This paper presents the results of a study on the compatibility of the teaching and learning styles for the mechanical engineering students and their instructors at the United Arab Emirates University.

\section{Teaching Styles}

Teaching style is the mechanism of how we convey the knowledge and information to students. Style also reflects what Reinsmith, 1992 and 1994 describes as the instructor's presence and the nature and quality of the encounter with students. As a result, the efficacy with which we display our styles as teachers has two effects on students. It may facilitate or hinder their ability to acquire content and skills and it influences the learning styles our students adopt.

Teachers' personal qualities direct the selection of the way they deliver the substance of the matter. There is a symbiotic relationship among personal qualities, the instructional processes teachers employ to convey the content of discipline, and the styles students display as learners, Grasha, A.F. (1994). .

Teaching styles are viewed as a particular pattern of needs, beliefs, and behaviors that faculty display in classrooms. The Grasha-Riechmann teaching style model was used in this study. The five teaching styles as defined by Anthony, 1994 are shown in the next subsection.

\section{Dimensions of Teaching Styles}

Expert: The instructor possesses knowledge that the students need. He strives to maintain status as an expert among students by displaying detailed knowledge and by challenging students to enhance their competence. He is concerned with transmitting information and insuring that students are well prepared.

Formal Authority: An instructor-centered approach where the instructor feels responsible for providing and controlling the flow of content which the student is to receive and assimilate. The formal authority figure does not concern himself with creating a relationship with the student nor is it important if the students build relationships with each other.

Demonstrator or Personal Model: An instructor-centered approach where the instructor demonstrates and models what is expected (skills and processes) and then acts as a coach or guide to assist the students in applying 
the knowledge. This style encourages student participation and utilizes various learning styles.

Facilitator: A student centered approach where the instructor facilitates and focuses on activities. Responsibility is placed on the students to take initiative to achieve results for the various tasks. Students who are independent, active, collaborative learners thrive in this environment. Instructors typically design group activities which necessitate active learning, student-to-student collaboration and problem solving.

Delegator: A student-centered approach whereby the instructor delegates and places much control and responsibility for learning on individuals or groups of students. This type of instructor will often require students to design and implement a complex learning project and will act solely in a consultative role. Students are often asked to work independently or in groups and must be able to effectively work in groups.

\section{Solomon-Felder Model for Learning Styles}

Student preferences in the reception and processing of information formulate the preferred learning style for a student. The compatibility between the instructor delivery style and the student learning style partially contributes to the percentage of the learning a student attains in a class. A mismatch between the instructor teaching style and the student style may lead to a failure in the learning process, Felder, 2005 and Coffield, 2004. There are a number of models, assessment tools and methodologies designed to test the learning styles Felder, 1988. In Engineering and Science Education two instruments have been widely recognized: Kolb's Learning Style Inventory (LSI) Kolb 1983 and Soloman-Felder Index of Learning Styles (ILS). The styles assessment tool is an opinion survey. In this study, the ILS assessment tool was used. It consists of 44 multiple-choice questions. The instrument is conveniently available on the internet, Soloman, 2008. The ILS model classifies students according to where they fit on a number of scales pertaining to the ways they receive and process information. The ILS model classifies learners along four dimensions; namely, (1) Active-Reflective, based on Kolb model for processing information, (2) Sensor-Intuitive, based on Jung's theory of psychological types, (3) Visual-Verbal, and (4) Sequential-Global. The last two dimensions are based of dimensions of other models, Grasha, 1994. The number of the possible different learning styles according to the ILS model is (24=16).

\section{Dimensions of Learning Styles}

In this study, the ILS assessment tool was utilized, Soloman 2008. This tool is based on responding to 44 multiple-choice questions designed to 
classify a respondent's learning style along four dimensions active-reflective, sensing-intuitive, visual-verbal and sequential-global dimensions.

\section{Active-Reflective}

This dimension deals with the processing of the perceived information. An active experimentation learner prefers to experiment with, discuss, test and explain the perceived information. Active learners prefer group work. Active learners tend to be experimentalists. Reflective observation learners prefer to examine and manipulate the information introspectively. Reflective learners prefer independent work. Reflective learners tend to be theoreticians. The active learning style is closely related with the $C$ and $D$ thinking styles, while the reflective learning style is closely related with the A thinking style.

\section{Sensor-Intuitive}

This dimension deals with the perception and organization of information. Sensing involves observing, gathering data through senses, intuition involves indirect perception through speculation, imagination and guessing. Sensor learners prefer facts, data and experimentation, solving problems using standard methods, memorizing facts. Intuitor learners prefer principles and theories, challenging new concepts, innovation and dislike repetition. The sensor learning style is closely related with the B thinking style, while the intuitive learning style is closely related with the D thinking style.

\section{Visual-Verbal}

This dimension deals with the input of information. Visual learners prefer information presented in pictures, diagrams, movies, demonstrations and charts. Verbal learners prefer information said to them. They prefer verbal discussion and presentation more than that presented by other input modalities.

\section{Sequential-Global}

This dimension deals with the understanding of the information. Sequential learners prefer an ordered progression in presenting the material while global learners like to see the whole scheme of the presentation in order to comprehend the information.

Sequential learning styles are closely related to the B thinking style while the global learning style is closely related to the D thinking style. 


\section{Results and Discussion}

The data for this research has been collected from 40 ME students from the UAEU. The Solomon-Felder model was utilized in order to assess the students' learning styles. A total of 12 instructors participated in the teaching style survey.

The dominant learning styles for the whole sample was analyzed statistically, the error in the statistics analysis assumes 5\% error. Figure 1 shows the distribution of the four dimensions of learning styles for all students who participated in the study. For each dimension, the distribution is shown from strong (9-11) to moderate (5-7) to weak (1-3) scale. Figures 2 a-d show the dominant learning styles for the whole student population at the mechanical engineering department at the UAEU. The negative notion is used to present the whole domain on the same figure as was used in Soloman , 2008. The negative scale is indicated for the first modality in each domain. For example in Figure 2-a, the negative is indicating a predominant active domain. Figures 2 a-d show that the majority of students are balanced active-reflective, intuitive-sensor, visual-verbal and sequential-global learners. There is however a small skew toward reflective, intuitive, global and verbal learning styles over active, sensor, visual and sequential learning styles, respectively.

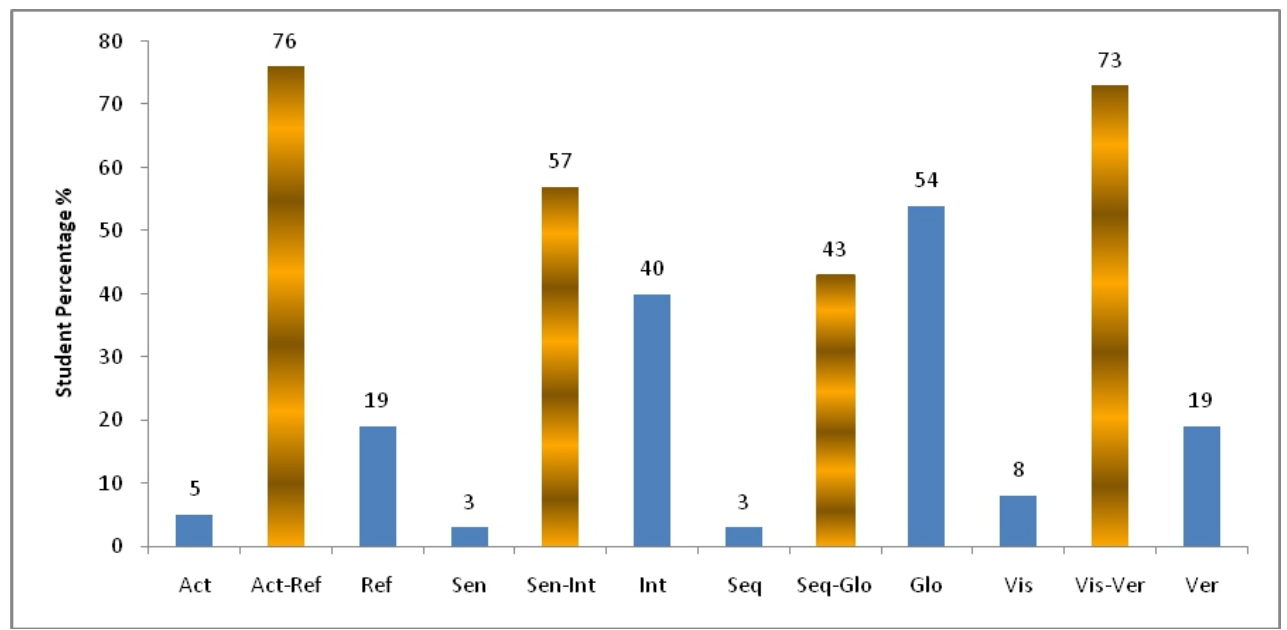

Figure 1. Mechanical engineering students learning styles at UAEU 

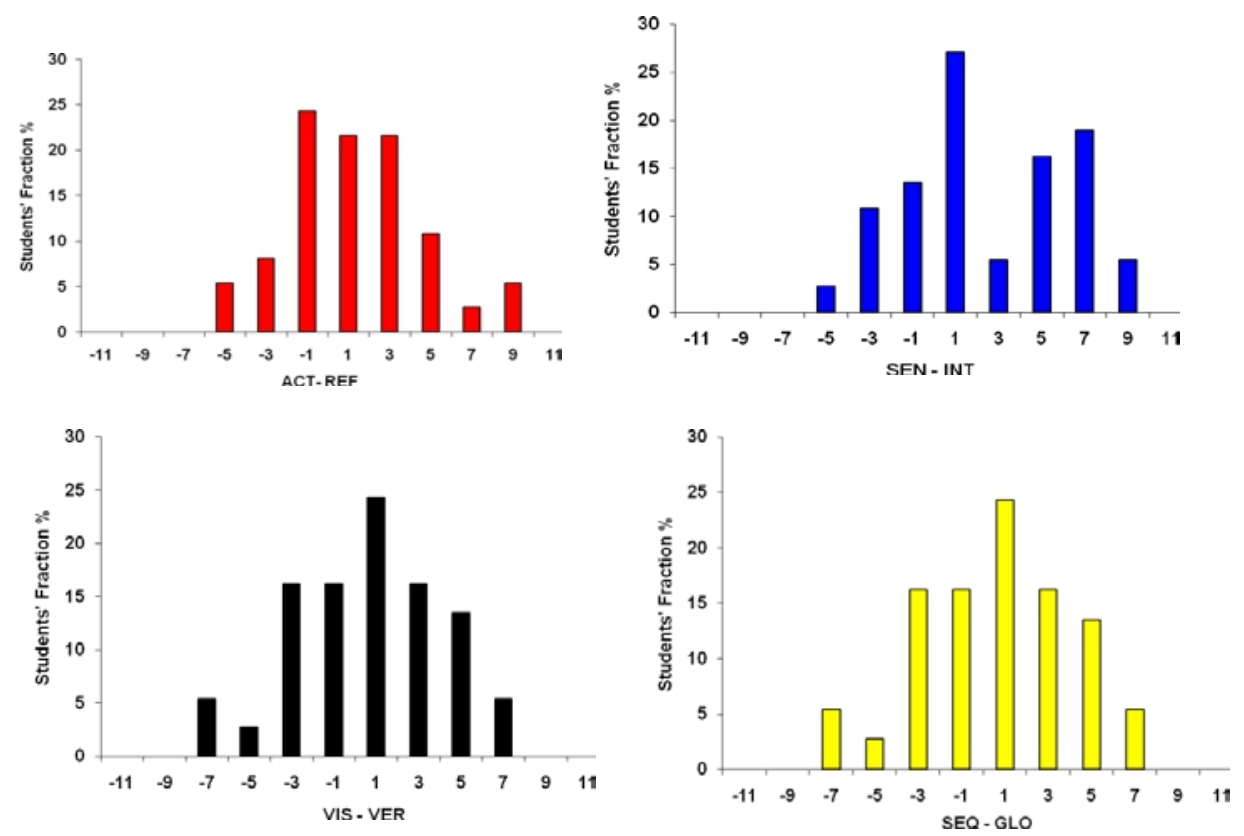

Figure 2. Mechanical engineering students learning styles distribution at UAEU a) activereflective, b) intuitive-sensor, c) visual-verbal and d)sequential-global

The teaching style survey results, shown in table 1, revealed that the ME faculty's primary teaching styles are expert, formal authority, personal model and delegator, whereas the secondary teaching style is the facilitator. Such a combination of teaching styles provides the students with information, knowledge, and skills that the instructors possess. The focus is on clear expectations and acceptable ways of doing things. The emphasis is on direct observation and by following a role model. Furthermore, it helps the students to perceive themselves as independent learners. However, the downfall for such a combination is that if the knowledge and the information the instructors possess are overused, it will be intimidating to less experienced students. It may not always show the underlying thought processes that produce answers. If the formal authority teaching style is strongly applied, it can lead to rigid, standardized, and less flexible ways of managing students and their concerns. The delegator teaching style may misread student's readiness for independent work. Some students may become anxious when given autonomy. 


\begin{tabular}{|c|c|c|c|c|c|}
\hline Teaching Style & Low & Moderate & High & Average Score & Remarks \\
\hline Expert & $1.0-3.2$ & $3.3-4.8$ & $4.9-7.0$ & $\mathbf{5 . 7}$ & High \\
\hline Formal Authority & $1.0-4.0$ & $4.1-5.4$ & $5.5-7.0$ & $\mathbf{5 . 5}$ & High \\
\hline Personal model & $1.0-4.3$ & $4.4-5.7$ & $5.8-7.0$ & $\mathbf{5 . 4}$ & Moderate \\
\hline Facilitator & $1.0-3.7$ & $3.8-5.3$ & $5.4-7.0$ & $\mathbf{5 . 3}$ & Moderate \\
\hline Delegator & $1.0-2.6$ & $2.7-4.2$ & $4.3-7.0$ & $\mathbf{4 . 7}$ & High \\
\hline
\end{tabular}

Table 1 Teaching Styles of the ME Faculty

\section{Conclusion}

Since the ME students learning style fall within the reflective-active range it is recommended that the $\mathrm{ME}$ instructors provide more discussions, problem-solving activities; students retain information better when doing something with it. At the same time, provide time to think about the material, not just read \& memorize; write summaries, devise questions and possible applications of the content.

$40 \%$ of the students prefer the intuitive learning style over sensing, while $57 \%$ are in the midrange of intuitive and sensing, therefore, it is recommended that the ME instructors should focus more on interpretations and theories which connect facts; provide time to read questions thoroughly and recheck results.

Most students preferred global learning style to the sequential. For such students, it is recommended to provide overviews of material before getting into specifics; show how topics are related to other relevant course material or knowledge students may have from previous experiences.

$73 \%$ of the students prefer both verbal and visual leaning styles. It is recommended to incorporate meaningful pictures, diagrams, charts, timelines, video, demonstrations whenever possible; concept maps are good for listing key points and demonstrating relationships and can be color-coded and to summarize or outline content verbally so that students can transcribe in their own words; working through ideas in groups can also be effective.

\section{References:}

Mamchur, Carolyn. (1996). A Teacher's Guide to Cognitive Type Theory \&Learning Style. Alexandria, VA: ASCD Publishing.

Sarasin, Lynne Celli. (1999) Learning Style Perspectives, Impact in the Classroom. Madison, WI: Atwood Publishing.

Gregorc, Anthony F. and Butler, Kathleen A. (1984). "Learning is a Matter of Style.” VocEd, v. 59, p. 27-29.

Anthony F. Grasha and Laurie Richlin (1996). "Teaching with Style: A Practical Guide to Enhancing Learning by Understanding Teaching and 
Learning Styles”. Alliance Publishers, div. of International ISBN: 9780964507111

Lage, M. J.,Platt, G. J. \& Treglia, M. (2000). Inverting the classroom: A gateway to creating an inclusive learning environment. Journal of Economic Education.

Moallem, M. (2001). The implications of the research literature on learning styles for the design and development of a Web-based course.Presented at the AECT 2001 Annual Conference.

Reinsmith, W.A. (1992). "Archetypal forms in teaching: A continuum". Westport, CN: Greenwood Press.

Reinsmith, W.A. (1994). "Archetypal forms in teaching”. College Teaching, 42, 131-136.

Grasha, A.F. (1994). A matter of style: The teacher as expert, formal authority, personal model, facilitator, and delegator. College Teaching,42, 142-149.

Felder, R. and Spurlin, J. (2005). “Application, reliability and validity of Index of Learning Styles,” International Journal of Engineering Education, Vol. 21, No. 1, pp. 103-112.

Coffield, F., Moseley, D., Hall, E., Ecclestone, K. (2004). "Learning Styles and Pedagogy in Post-16 Learning: A Systematic and Critical Review Learning and Skill Research Center Report, available on line www.LSRC.ac.uk.

Felder R. M., Silverman L K (1988). "Learning and Teaching Styles in Engineering Education, Engineering Education Vol 78, No. 7, pp. 674-681.

Kolb, D. (1983). "Experimental Learning: Experience as the Source of Learning and Development”. New York: Prentice Hall.

Soloman, B., and Felder, R. M.. "Index of Learning Styles," http://www.ncsu.edu/felder- public/ILSpage.html) [Acessed May 1, 2008]. 